\title{
Review
}

Jie Ming Yeo, Vivian Tse, Judy Kung, Hiu Yu Lin, Yee Ting Lee, Joseph Kwan, Bryan P. Yan and Gary Tse*

\section{Isolated heart models for studying cardiac electrophysiology: a historical perspective and recent advances}

DOI 10.1515/jbcpp-2016-0110

Received July 18, 2016; accepted October 12, 2016; previously published online January 7, 2017

\begin{abstract}
Experimental models used in cardiovascular research range from cellular to whole heart preparations. Isolated whole hearts show higher levels of structural and functional integration than lower level models such as tissues or cellular fragments. Cardiovascular diseases are multi-factorial problems that are dependent on highly organized structures rather than on molecular or cellular components alone. This article first provides a general introduction on the animal models of cardiovascular diseases. It is followed by a detailed overview and a historical perspective of the different isolated heart systems with a particular focus on the Langendorff perfusion method for the study of cardiac arrhythmias. The choice of species, perfusion method, and perfusate composition are discussed in further detail with particular considerations of the theoretical and practical aspects of experimental settings.
\end{abstract}

*Corresponding author: Dr. Gary Tse, MBBS MA PhD FRSPH FIBMS FESC, Department of Medicine and Therapeutics, The Chinese University of Hong Kong, 30-32 Ngan Shing Street, Shatin, Hong Kong, SAR, P.R. China, Phone: +852 39177548, Fax: +852 28170857 , E-mail: tseg@cuhk.edu.hk; and Li Ka Shing Institute of Health Sciences, Chinese University of Hong Kong, Hong Kong, SAR, P.R. China

Jie Ming Yeo: School of Medicine, Imperial College London, London, UK

Vivian Tse: Department of Physiology, McGill University, Montreal, Quebec, Canada

Judy Kung, Hiu Yu Lin and Yee Ting Lee: School of Biomedical Sciences, Li Ka Shing Faculty of Medicine, University of Hong Kong, Hong Kong, SAR, P.R. China

Joseph Kwan: Department of Medicine, Li Ka Shing Faculty of Medicine, University of Hong Kong, Hong Kong, SAR, P.R. China Bryan P. Yan: Department of Epidemiology and Preventive Medicine, Monash University, Melbourne, Australia; and Department of Medicine and Therapeutics, Chinese University of Hong Kong, Hong Kong, SAR, P.R. China
Keywords: animal models; cardiac electrophysiology; Langendorff mode; perfusate composition; perfusion methods; species differences; working mode.

\section{Introduction}

Animals have been used to study diseases affecting humans. However, there is a general compromise between clinical relevance and experimental utility when using animal models [1]. The advantages are that the further one moves away from using human tissues, usually the quality, quantity and reproducibility of the data are greater, and the cost incurred are lower. However, these may be offset by the model bearing less relevance to the human condition concerned. Therefore, experimental designs must balance these conflicting factors. Experimental models used in cardiovascular research range from cellular to whole heart preparations. Isolated whole hearts show higher levels of structural and functional integration than lower level models such as tissues or cellular fragments. Cardiovascular diseases are multi-factorial problems that are dependent on highly organized structures rather than on molecular or cellular components alone [2]. The use of intact hearts in the study of cardiac arrhythmias, therefore, has the advantage of being physiologically more relevant. There are many variations in the design of these whole heart models, including the choice of species, perfusion method, and perfusate composition. These factors are discussed in turn.

\section{Species}

Many animal species have been used for cardiovascular research. They can be divided into two groups, small animals such as the mouse, rat, guinea pig and rabbit, and large animals such as the dog, pig, and sheep [3-8]. 
An important factor in deciding which model to use is cost. Despite the increasing amount of funding invested in biomedical research [9], there are often financial constraints at the levels of individual research groups, institutions and commercial corporations [10], meaning that resources need to be used efficiently and responsibly. As a result, small animals are more commonly selected because they consume less food and occupy less space, and are thus cheaper to maintain than large animals. However, other factors such as the experimental conditions required also determine the choice of the species. For example, experimental studies in mice have accelerated our understanding of the pathophysiology of cardiovascular diseases [11]. Mice grow and reproduce rapidly, which allow greater number of experiments to be conducted within a defined period of time. Although they show important differences to humans in terms of their physiology, their amenability to genetic manipulation means that they are very useful for studying the consequences of single mutations in cardiac arrhythmias [12-15]. Mice have also been used to study macrovascular complications of cardio-metabolic disorders such as hypertension and diabetes mellitus [16, 17], demonstrating the critical role endothelial dysfunction plays in their disease pathogenesis. Identification of the molecular events is crucial for the development of future therapy to improve endothelial dysfunction, which could potentially slow down or even reverse the progression of these conditions [18-22]. It is because of these reasons that mice are almost used ubiquitously in biomedical research institutions.

However, the use of mice for studying cardiac electrophysiology is not without limitations. Firstly, mouse hearts are electrically more stable than human hearts because of their small sizes. Spontaneous ventricular arrhythmias are, therefore, less likely to occur [23]. Secondly, arrhythmias are easier to reverse in mice than in larger species, making them invaluable for the evaluation of the effectiveness of anti-arrhythmic drugs, but efficacy could be overestimated. There are also other important differences between mouse and human cardiac electrophysiology. For example, the resting heart rate in the mouse is around 600 beats per minute, whereas that of humans is 60 beats per minute [24]. The shapes of cardiac action potentials also differ between these species, due to differing repolarizing currents. In mice, action potentials have shorter durations and do not have a plateau phase [25] that is observed in larger species such as humans. The explanation is that $I_{\text {to }}$ is the major repolarizing current whereas $I_{\mathrm{Kr}}$ and $I_{\mathrm{Ks}}$ have a lesser role in mice [26]. By contrast, $I_{\mathrm{Kr}}$ and $I_{\mathrm{Ks}}$ play predominant roles in ventricular repolarization of human hearts [27]. Moreover, calcium handling in cardiomyocytes in mice is different. Calcium reuptake almost exclusively involves sarcoplasmic reticulum $\mathrm{Ca}^{2+}-\mathrm{ATPase}$ with little contribution from the $\mathrm{Na}^{+}-\mathrm{Ca}^{2+}$ exchanger (NCX) [28, 29]. By contrast, NCX plays a greater role in humans and exploration of its contributions to arrhythmogenesis, therefore, requires the use of species other than mice. The use of other popular species such as rabbits [30-37] and guinea pigs [35, 38-45] has provided much insights into the mechanisms of arrhythmic disorders. Although guinea pigs lack $I_{\text {to }}$, they possess rectifier currents that make the particularly suitable for repolarization disorders such as long QT syndromes [46-49].

By contrast, larger animals have better approximations in terms of heart size and musculature, and, therefore, have closer hemodynamic parameters, such as coronary blood flow and cardiac output, to humans than smaller animals [50-53]. As a result, sheep hearts have been used as a model system for testing of prosthetic heart valves [54-56]. Dog and rabbit hearts have ionic currents that correspond to those found in human hearts, with similar morphology and duration of the cardiac action potential observed [30-33, 57, 58]. They are, therefore, useful for investigating electrophysiological mechanisms underlying cardiac arrhythmias and the experimental data obtained from them bear greater clinical relevance to the human conditions. However, disadvantages are that large volumes of fluid for perfusion are needed and the experimental apparatus are large and cumbersome when compared to experiments conducted in smaller animal species such as rats and mice [59-63].

\section{Perfusion method}

Elias Cyon was among the first investigators to devise the isolated frog heart model [64]. The frog is distinct from mammals in that it is a cold-blooded species. Its heart has only three chambers, with two atria and a single ventricle, rather than the four chambers, with two atria and two ventricles, found in mammalian hearts. The frog heart has no coronary circulatory system and the exchange of gases and metabolites takes place by diffusion. In the perfusion setup by Cyon, the cannula is inserted into the vena cava. A pump is then used to deliver serum obtained from rabbit blood through the cannula and into the vena cava. The serum is then ejected via into the aorta, through a glass tube and back to the vena cava. The circulatory system is surrounded by a glass cylinder that is filled with fluid. The temperature of the heart preparations can be kept constant or altered using this fluid. 


\section{Langendorff heart}

Based on Cyon's frog heart model, the isolated perfused mammalian heart model was established in 1897 by Oscar Langendorff [65], after whom the perfusion method is named [66]. In the original experiments performed by Langendorff, hearts from cats, dogs, and rabbits were used. In his setup, a cannula is inserted and fixed in the ascending aorta to allow the delivery of blood into the heart in a retrograde manner. This causes the aortic valve to shut, and thus the perfusate is unable to fill the left ventricle. Instead, it enters the coronary arteries via the ostia, passes through the coronary circulation, and drains into the right atrium via the coronary sinus. Once perfusion starts, the heart is resuscitated, after which it regains its normal automaticity and can continue to beat spontaneously for several hours. This discovery led Langendorff to conclude that the heart receives oxygen and nutrients from the coronary arteries because their perfusion is sufficient to induce the normal heart beat. His other contributions led to the demonstrations of many important physiological findings $[65,67]$, which include the following: (1) introduction of potassium chloride to the heart is sufficient to cause cardiac arrest; (2) muscarine exerts negative chronotropic and inotropic effects on the heart, eventually causing diastolic arrest, and that atropine exerts effects opposite to muscarine; (3) increased and decreased temperatures resulted in sinus tachycardia and bradycardia, respectively; and (4) ligation of coronary arteries led to cardiac failure and subsequent arrest.

In Langendorff's experimental system, the perfusate was delivered at a constant hydrostatic pressure. This was achieved by keeping the level of the reservoir constant. He was able to estimate coronary flow based on volumetric determination of the coronary effluent that emerged from the right atrium over time. However, coronary flow measurements using this method had several limitations, as pointed out previously [68]. Firstly, they were not accurate, as outflow from the heart could take place without the perfusate having first passed through the coronary circulation because of aortic valve incompetence [69]. Secondly, they were not instantaneous because there was a lag between changes in the coronary vessels and the arrival of the perfusate at the recorder [70]. Finally, they were not always continuous, and so could not detect transient changes in flow rate. Nowadays, the flow rate can be determined more accurately by using a flow meter.

Katz subsequently modified Langendorff's constant pressure method, developing a system that instead delivered the perfusate at a constant flow rate [71]. This was achieved by the addition of a peristaltic roller pump between the reservoir and the heart. In this setup, a pressure transducer is used to measure the changes in coronary pressure as an index of vessel resistance. An advantage of this method is that the pressure transducer was more sensitive, making it possible to monitor coronary flow continuously and instantaneously [72]. An example of an electrophysiology rig in Langendorff perfusion mode using a constant flow rate is shown in Figure 1. Using this setup, the electrophysiological mechanisms underlying arrhythmogenesis in different disease models can be examined using different pacing protocols. For example, an increase in the incidence of triggered activity was observed during regular pacing under hypokalemic conditions (Figure 2, left). Moreover, ventricular arrhythmias were induced during S1S2 pacing (Figure 2, right), where action potential duration (APD) alternans, which arise under conditions of steep APD restitution, were thought to increase the likelihood of reentry (Figure 3). The reader is directed to this article here for the mechanisms that generate triggered (Figure 4) and reentrant (Figure 5) arrhythmogenesis [75].

The decision as to which system to use depends on the precise experimental requirements. For example, perfusion at a constant flow rate overrides the autoregulatory mechanisms of the coronary vessels. Therefore, they do not automatically alter the amount of perfusate delivered to the whole heart when there is increased work, perhaps caused by an increased heart rate from more rapid pacing, or administration of inotropic agents or other drugs [70]. This can lead to ischemia when the perfusion cannot match the increased metabolic demands of the working myocardium [76]. Arguably, it is more physiological to

\section{Langendorff-perfused mouse heart}

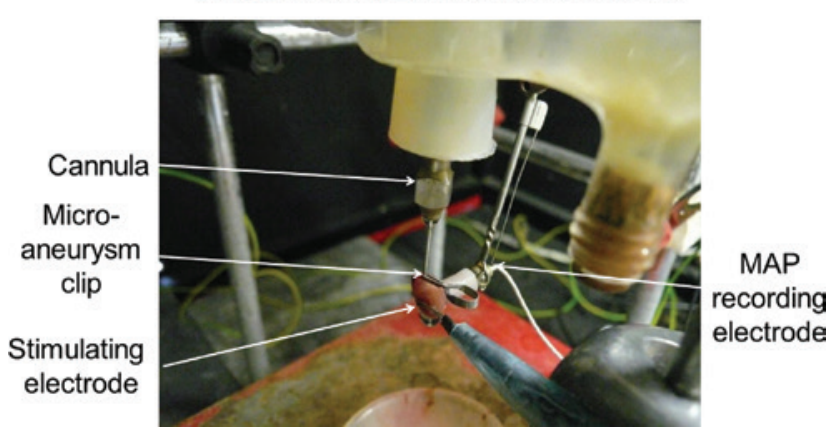

Figure 1: An experimental rig used for examining electrophysiological properties in mouse hearts using the Langendorff perfusion method at a constant flow rate.

The Figure has been reproduced from Choy et al. (2016) with permission [73]. 


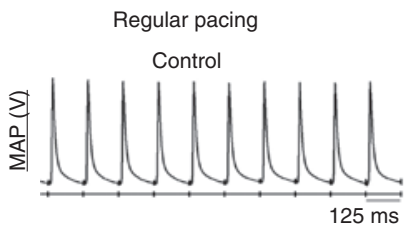

Programmed electrical stimulation

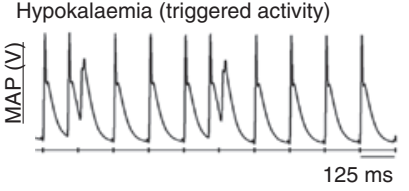
Control

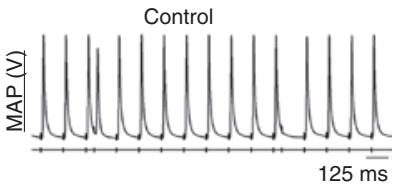

Hypokalaemia (induced VT)

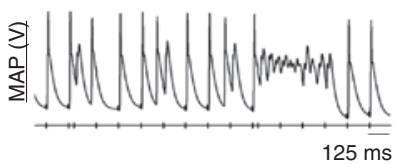

Figure 2: An example of a disease model for studying the mechanisms of cardiac arrhythmias.

Hypokalaemia prolongs APDs, which predisposes to triggered activity (left). This AP prolongation and reduced refractoriness together form a re-entrant substrate. The use of programmed electrical stimulation can reliably provoke ventricular arrhythmias (right). The Figure has been reproduced from Choy et al. (2016) with permission [73]. Original traces have been reproduced from Tse et al. (2016) [74] with permission.

use a constant pressure setup because intact autoregulatory mechanisms permit perfusion matching with tissue demand [77]. However, there are potential problems in using a constant pressure setup in arrhythmogenicity studies. Normally in a regular rhythm, the ventricular

pressure exceeds the perfusion pressure during systole. By contrast, during ventricular tachy-arrhythmias, ventricular pressure will drop below the perfusion pressure. The occurrence of these arrhythmias would lead to a variable contractile state, which can have an adverse influence on global and regional perfusion in the constant pressure mode, leading to confounding factors such as ischemia.

\section{Ejecting heart}

Other perfusion modes in addition to the Langendorff method have also been devised. The ejecting heart preparation pioneered by Neely and Morgan in rats [78, 79], also known as the working heart, was capable of performing physiologically relevant, mechanical work. In this system, the aorta was attached to an aortic outflow line whereas the left atrium was connected to the atrial inflow line. The latter delivered perfusate at a constant hydrostatic pressure to the left atrium (preload). As the left ventricle contracted and relaxed, the perfusate left the aortic outflow line against a constant hydrostatic pressure (afterload). The advantage of this system is that delivery of the perfusate to the working myocardium is

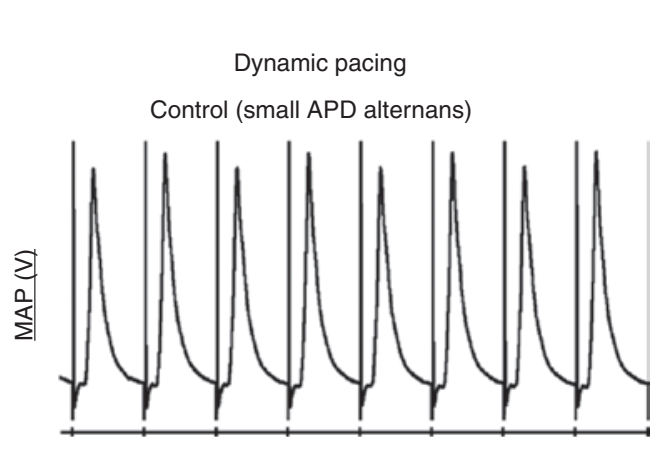

Hypokalaemia (exacerbated APD alternans)

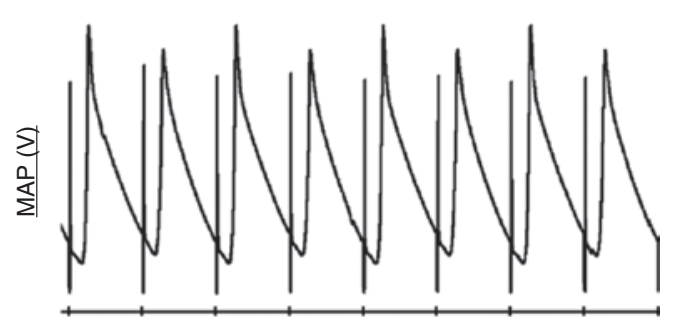

Restitution curves

Control (normal APD restitution)

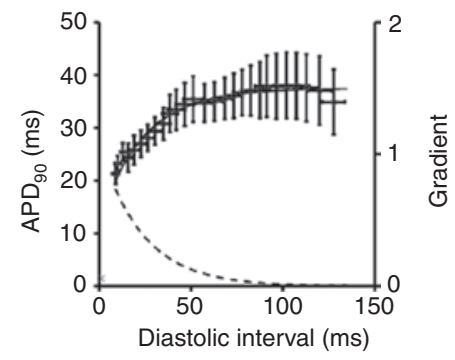

Hypokalaemia (steep APD restitution)

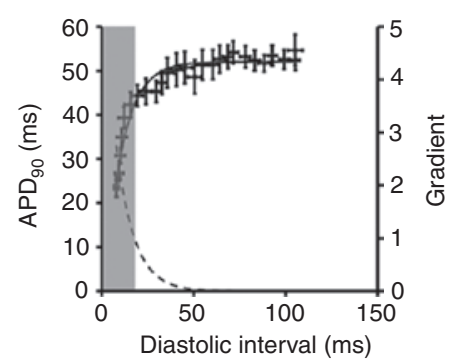

Figure 3: Hypokalaemia exacerbates APD alternans at fast heart rates (left) due to steep APD restitution (right). The Figure has been reproduced from Choy et al. (2016) with permission [73]. Original traces have been reproduced from Tse et al. (2016) [74] with permission. 


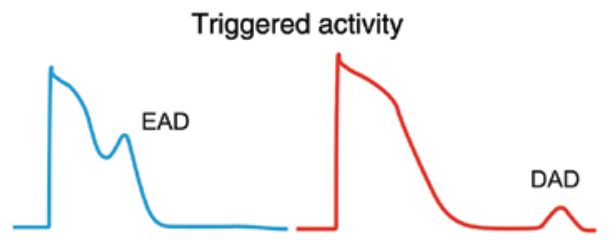

Figure 4: Triggered activity can arise from early or delayed afterdepolarizations, respectively.

The Figure has been adapted from Tse et al. (2016) with permission [75].

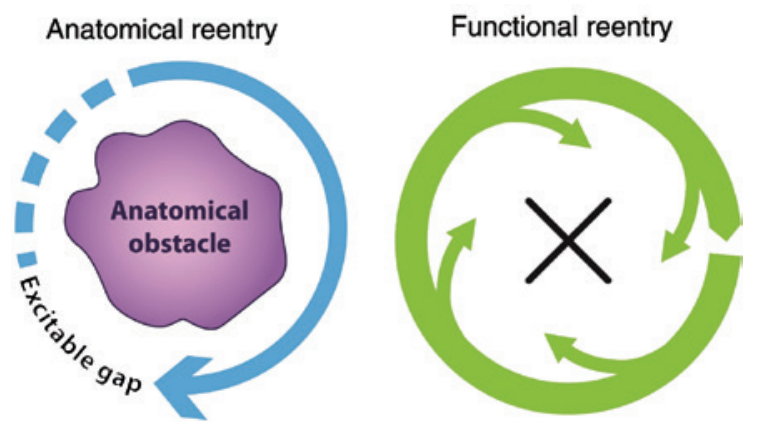

Figure 5: Circus-type re-entry can involve an anatomical (left) or functional (right) obstacle, around which the action potential wave can travel.

The Figure has been adapted from Tse et al. (2016) with permission [75].

more physiological, involving orthograde perfusion of coronary arteries rather than retrograde perfusion in the Langendorff mode.

\section{Other isolated heart models}

The right-side working mode combines retrograde flow of the Langendorff perfusion through the aorta with antegrade flow through the right atrium and ventricle [80]. In the four-chamber working mode, the perfusate is circulated through the heart in a physiological manner, as two pumps provide input flows into the right and left atria simultaneously [81]. This differs from the Langendorff perfusion method in many respects [80]. Firstly, it involves two-way flow through the aorta, whereas the Langendorff perfusion method allows only retrograde flow. Secondly, it results in all four cardiac chambers being filled with changing volumes, preserving the natural flow through the heart. Thirdly, in this mode the aortic valve opens and closes as the heart contracts and relaxes, whereas in the Langendorff mode the aortic valve is kept shut by the retrograde perfusion. Finally, in this mode the coronary flow is determined by the heart itself, whereas in the Langendorff mode it is determined by the rate set by the peristaltic roller pump.

\section{Insights into cardiac electrophysiology from the use of isolated hearts}

There are advantages of using isolated hearts as the primary experimental system. Firstly, they allow the investigation of changes in cardiac parameters independent of systemic influences [82], including those of the central [83] and autonomic [84, 85] nervous systems (ANS) [86]. For example, denervation of the heart removes the confounding effects of the ANS, which is important because sympathetic and vagal stimulation exerts an important source of influence on arrhythmogenesis [87]. If one wishes to investigate the contributions of the ANS, then sympathomimetic or parasympathomimetic agents can simply be added to the perfusate solutions [88]. It was originally assumed that the use of such agents would simulate the endogenous effects of autonomic input into the heart. However, it was found that their effects differed from those obtained by stimulation of intact autonomic nerves, as eloquently demonstrated by Ng's group [89]. Ng and colleagues elegantly designed a modified version of the Langendorff preparation with intact dual autonomic innervation using rabbit hearts [90]. Since then, this model has been extensively used to explore the effects of direct stimulation of sympathetic and parasympathetic nerves on cardiac physiology, such as heart rate [91], $\mathrm{Ca}^{2+}$ handling and contractile force development [92, 93], electrical restitution and alternans [94-96] and arrhythmogenesis [97, 98].

Secondly, the isolated intact heart is more physiological than lower levels of organizational structures such as tissues and cells. Indeed, the Langendorff heart model has been an valuable tool for drug cardiotoxicity screening [99] and for exploration of the roles of conduction or repolarization abnormalities in cardiac arrhythmogenesis in different disease models [100-103]. For example, the arrhythmogenic effects of doxorubin-induced heart failure were examined under different loading conditions [104]. A low incidence of arrhythmias was observed during unloading (Langendorff mode). Imposition of a higher preload (in the working mode) produced greater arrhythmia inducibility that was associated with shortening of both APDs and effective refractory periods. Moreover, experiments conducted in mouse hearts have shed light into distinct roles of triggered activity and reentry, and the electrophysiological mechanisms responsible for their 
generation [73]. The use of isolated heart systems in preclinical studies have provided much insights for translational application, such as the development of novel risk markers for stratifying arrhythmic risk in human populations [105-110].

To enhance the validity of experimental data arising from pre-clinical research, the Lambeth Conventions II was held in 2010, which led to the development of guidelines on experimental design, choice of animal species to model human conditions, and the methodology used to induce disease processes, as well as definitions of different types of arrhythmias [111].

\section{Perfusate composition}

The different types of perfusates can be divided into crystalloid, colloid and cell based solutions, which will be discussed in turn. The most commonly used perfusate for maintaining cardiac viability is based on the crystalloid buffer solution described by Krebs and Henseleit in 1932 [112]. It has the following composition with the respective concentrations indicated in brackets: $\mathrm{NaCl}(118.5 \mathrm{mM})$, $\mathrm{NaHCO}_{3}$ (25.0 mM), $\mathrm{KCl}(4.7 \mathrm{mM}), \mathrm{MgSO}_{4}(1.2 \mathrm{mM}), \mathrm{KH}_{2} \mathrm{PO}_{4}$ (1.2 mM), glucose (11 mM), and $\mathrm{CaCl}_{2}(2.5 \mathrm{mM})$. The composition of the Krebs-Henseleit buffer solution is meant to mimic that of plasma in the blood. However, this original formulation did not take into account the binding of calcium to plasma proteins, with the consequence that its calcium content at $2.5 \mathrm{mM}$ was approximately twice the amount of the ionized calcium normally present in plasma. Since then, investigators have used lower $\mathrm{CaCl}_{2}$ concentrations of $1.2-1.8 \mathrm{mM}$ that better represent the physiological concentrations found in plasma [113]. Glucose is often chosen as the only substrate in the buffer solution, relying on the ability of the heart to utilize any metabolic substrate as a source of energy. This is despite the heart normally uses fatty acids as the main energy source in vivo [114], which normally account for 64\% and glucose accounting for $26 \%$ of ATP production (the remaining percentage is from glycolysis) in the mouse heart [115] with similar relative contributions in other species. A likely reason for the choice of glucose rather than fatty acids is that it is difficult to dissolve the latter in aqueous solutions, with the complication that frothing occurs when the solution containing fatty acids is gassed [116]. In a solution that contains both calcium and phosphate ions, there is a risk of precipitation, forming calcium phosphate particles that will block the coronary arteries and destroy the heart preparation. Thus, the perfusate is bubbled with $5 \% \mathrm{CO}_{2}$ to lower the $\mathrm{pH}$, before adding $\mathrm{CaCl}_{2}$ and $\mathrm{KH}_{2} \mathrm{PO}_{4}$ because the increase in acidity inhibits their precipitation. The perfusate is also passed through a $5 \mu \mathrm{m}$ filter to remove particles of impurities for the same reason. The lack of plasma proteins in the Krebs-Henseleit buffer solution results in a lower oncotic pressure than that of the blood [117]. This has the disadvantage of causing edema, as suggested by the increased accumulation of total tissue water [118]. The lack of hemoglobin or other oxygen-binding proteins limits the oxygen-carrying capacity of the perfusate. Nevertheless, bubbling with $95 \% \mathrm{O}_{2}$ compensates for this because the perfusate would then have a higher partial pressure of oxygen that is sufficient for keeping the heart preparations viable [88].

In addition to crystalloid solutions described earlier, colloid solutions and cell-based perfusates have also been used [119]. Colloid solutions can limit the myocardial edema induced by large changes in osmolarity caused by crystalloid solutions [120]. Furthermore, perfusate containing red blood cells and plasma preserve myocardial function better compared to perfusates containing either red blood cell concentrate or acellular hemoglobin-based oxygen carrier in porcine hearts [121]. The most obvious disadvantage is the time needed to prepare these solutions and the higher costs of its use. Moreover, traditional gassing methods can cause foam formation and physical damage to the red blood cells [122].

\section{Conclusions}

This article reviewed the different experimental setups that can be used for investigating cardiac electrophysiology, with particular considerations of species, perfusion method, and perfusate composition. Both small and large animals can be used for experimentation and the decision as to which species to use depends upon cost and nature of the pathological conditions studied. Both Langendorff and working heart methods have proven to be an extremely useful system, whose use has led to opportunities for translational application and better understanding of the mechanisms underlying cardiac arrhythmogenesis.

Acknowledgments: GT thanks the Croucher Foundation of Hong Kong for its generous support for his clinical assistant professorship and project grant, and the Faculty of Medicine, The Chinese University of Hong Kong for research funding. 
Author contributions: All the authors have accepted responsibility for the entire content of this submitted manuscript and approved submission.

Research funding: Croucher Foundation of Hong Kong, Clinical Assistant Professorship.

Employment or leadership: None declared.

Honorarium: None declared.

Competing interests: The funding organization(s) played no role in the study design; in the collection, analysis, and interpretation of data; in the writing of the report; or in the decision to submit the report for publication.

\section{References}

1. Hearse DJ, Sutherland FJ. Experimental models for the study of cardiovascular function and disease. Pharmacol Res 2000;41:597-603.

2. Fink M, Noble D. Pharmacodynamic effects in the cardiovascular system: the modeller's view. Basic Clin Pharmacol Toxicol 2010;106:243-9.

3. Hu Z, Chen Z, Wang Y, Jiang J, Tse G, Xu W, et al. Effects of granulocyte colony-stimulating factor on rabbit carotid and swine heart models of chronic obliterative arterial disease. Mol Med Rep 2016.

4. Szel T, Koncz I, Antzelevitch C. Cellular mechanisms underlying the effects of milrinone and cilostazol to suppress arrhythmogenesis associated with Brugada syndrome. Heart Rhythm 2013;10:1720-7.

5. Palatinus JA, Gourdie RG. Diabetes increases cryoinjury size with associated effects on Cx43 gap junction function and phosphorylation in the mouse heart. J Diabetes Res 2016;2016:8789617.

6. George SA, Sciuto KJ, Lin J, Salama ME, Keener JP, Gourdie RG, et al. Extracellular sodium and potassium levels modulate cardiac conduction in mice heterozygous null for the Connexin43 gene. Pflugers Arch 2015;467:2287-97.

7. Veeraraghavan R, Gourdie RG, Poelzing S. Mechanisms of cardiac conduction: a history of revisions. Am J Physiol Heart Circ Physiol 2014;306:H619-27.

8. Gourdie RG, Green CR, Severs NJ, Anderson RH, Thompson RP. Evidence for a distinct gap-junctional phenotype in ventricular conduction tissues of the developing and mature avian heart. Circ Res 1993;72:278-89.

9. Moses Hr, Dorsey ER, Matheson DH, Thier S. Financial anatomy of biomedical research. J Am Med Assoc 2005;294:1333-42.

10. Hall BH. The financing of research and development. Oxf Rev Econ Policy 2002;18:35-51.

11. Paton W. Man and mouse: animals in medical research. Oxford: Oxford University Press, 1984.

12. Tse G, Wong ST, Tse V, Yeo JM. Depolarization vs. repolarization: what is the mechanism of ventricular arrhythmogenesis underlying sodium channel haploinsufficiency in mouse hearts? Acta Physiol (Oxf) 2016;218:234-5.

13. Tse G, Wong ST, Tse V, Yeo JM. Variability in local action potential durations, dispersion of repolarization and wavelength restitution in aged wild-type and Scn5a+/- mouse hearts modelling human Brugada syndrome. J Geriatr Cardiol 2016.
14. Tse G, Wong ST, Tse V, Yeo JM. Determination of action potential wavelength restitution in Scn5a+/- mouse hearts modelling human Brugada syndrome. J Geriatr Cardiol 2016.

15. Tse G, Li KH, Laxton V, Chan YW, Keung W, Li RA, et al. Electrophysiological mechanisms of Brugada syndrome: insights from pre-clinical and clinical studies. Front Physiol 2016;7:467.

16. Xu A, Huang Y. A Tireless Giant in Vascular Research. J Cardiovasc Pharmacol 2016;67:359-60.

17. Tse G, Yan BP, Chan YW, Tian XY, Huang Y. Reactive oxygen species, endoplasmic reticulum stress and mitochondrial dysfunction: the link with cardiac arrhythmogenesis. Front Physiol 2016;7:313.

18. Zhang H, Liu J, Qu D, Wang L, Luo JY, Lau CW, et al. Inhibition of miR-200c restores endothelial function in diabetic mice through suppression of COX-2. Diabetes 2016;65:1196-207.

19. Zheng H, Pu SY, Fan XF, Li XS, Zhang Y, Yuan J, et al. Treatment with angiotensin-(1-9) alleviates the cardiomyopathy in streptozotocin-induced diabetic rats. Biochem Pharmacol 2015;95:38-45.

20. Zhang Y, Liu J, Luo JY, Tian XY, Cheang WS, Xu J, et al. Upregulation of angiotensin (1-7)-mediated signaling preserves endothelial function through reducing oxidative stress in diabetes. Antioxid Redox Signal 2015;23:880-92.

21. Murugan D, Lau YS, Lau WC, Mustafa MR, Huang Y. Angiotensin 1-7 protects against angiotensin II-induced endoplasmic reticulum stress and endothelial dysfunction via Mas receptor. PLoS One 2015;10:e0145413.

22. Cheang WS, Tian XY, Wong WT, Lau CW, Lee SS, Chen ZY, et al. Metformin protects endothelial function in diet-induced obese mice by inhibition of endoplasmic reticulum stress through $5^{\prime}$ adenosine monophosphate-activated protein kinase-peroxisome proliferator-activated receptor delta pathway. Arterioscler Thromb Vasc Biol 2014;34:830-6.

23. London B. Mouse models of cardiac arrhythmias. In: Saunders $\mathrm{JH}$, editor. Cardiac electrophysiology: from cell to bedside, 4th ed. Philadelphia, PA, 2004:433-43.

24. London B. Cardiac arrhythmias: from (transgenic) mice to men. J Cardiovasc Electrophysiol 2001;12:1089-91.

25. Baker LC, London B, Choi BR, Koren G, Salama G. Enhanced dispersion of repolarization and refractoriness in transgenic mouse hearts promotes reentrant ventricular tachycardia. Circ Res 2000;86:396-407.

26. Wang L, Swirp S, Duff H. Age-dependent response of the electrocardiogram to $\mathrm{K}(+)$ channel blockers in mice. Am J Physiol Cell Physiol 2000;278:C73-80.

27. Nerbonne JM. Molecular basis of functional voltage-gated K+ channel diversity in the mammalian myocardium. J Physiol 2000;525:285-98.

28. Bers DM. Cardiac excitation-contraction coupling. Nature 2002;415:198-205.

29. Bers DM, Despa S. Na/K-ATPase - an integral player in the adrenergic fight-or-flight response. Trends Cardiovasc Med 2009;19:111-8.

30. Kettlewell S, Burton FL, Smith GL, Workman AJ. Chronic myocardial infarction promotes atrial action potential alternans, afterdepolarizations, and fibrillation. Cardiovasc Res 2013;99:215-24.

31. Workman AJ, Kane KA, Rankin AC. Rate-dependency of action potential duration and refractoriness in isolated myocytes from the rabbit AV node and atrium. J Mol Cell Cardiol 2000;32:1525-37. 
32. Workman AJ, Kane KA, Rankin AC. Ionic basis of a differential effect of adenosine on refractoriness in rabbit AV nodal and atrial isolated myocytes. Cardiovasc Res 1999;43:974-84.

33. Workman AJ, Marshall GE, Rankin AC, Smith GL, Dempster J. Transient outward $\mathrm{K}+$ current reduction prolongs action potentials and promotes afterdepolarisations: a dynamic-clamp study in human and rabbit cardiac atrial myocytes. J Physiol 2012;590:4289-305.

34. Hsieh YC, Lin SF, Huang JL, Hung CY, Lin JC, Liao YC, et al. Moderate hypothermia (33C) decreases the susceptibility to pacing-induced ventricular fibrillation compared with severe hypothermia (30C) by attenuating spatially discordant alternans in isolated rabbit hearts. Acta Cardiol Sin 2014;30:455-65.

35. Osadchii OE. Impact of hypokalemia on electromechanical window, excitation wavelength and repolarization gradients in guinea-pig and rabbit hearts. PLoS One 2014;9:e105599.

36. Ng GA, Cobbe SM, Smith GL. Non-uniform prolongation of intracellular Ca2+ transients recorded from the epicardial surface of isolated hearts from rabbits with heart failure. Cardiovasc Res 1998;37:489-502.

37. Chang C-J, Cheng C-C, Chen Y-C, Kao Y-H, Chen S-A, Chen Y-J. Gap junction modifiers regulate electrical activities of the sinoatrial node and pulmonary vein: therapeutic implications in atrial arrhythmogenesis. Int J Cardiol 2016;221:529-36.

38. Osadchii OE. Effects of ventricular pacing protocol on electrical restitution assessments in guinea-pig heart. Exp Physiol 2012;97:807-21.

39. Osadchii OE. Flecainide attenuates rate adaptation of ventricular repolarization in guinea-pig heart. Scand Cardiovasc 2016;50:28-35.

40. Osadchii OE. Impaired epicardial activation-repolarization coupling contributes to the proarrhythmic effects of hypokalaemia and dofetilide in guinea pig ventricles. Acta Physiol (Oxf) 2014;211:48-60.

41. Osadchii OE. Flecainide-induced proarrhythmia is attributed to abnormal changes in repolarization and refractoriness in perfused guinea-pig heart. J Cardiovasc Pharmacol 2012;60:456-66.

42. Osadchii OE. Dofetilide promotes repolarization abnormalities in perfused Guinea-pig heart. Cardiovasc Drugs Ther 2012;26:489-500.

43. Osadchii OE. Quinidine elicits proarrhythmic changes in ventricular repolarization and refractoriness in guinea-pig. Can J Physiol Pharmacol 2013;91:306-15.

44. Osadchii OE, Bentzen BH, Olesen SP. Chamber-specific effects of hypokalaemia on ventricular arrhythmogenicity in isolated, perfused guinea-pig heart. Exp Physiol 2009;94:434-46.

45. Osadchii OE, Olesen SP. Electrophysiological determinants of hypokalaemia-induced arrhythmogenicity in the guinea-pig heart. Acta Physiol (Oxf) 2009;197:273-87.

46. Brunner M, Peng X, Liu GX, Ren XQ, Ziv O, Choi BR, et al. Mechanisms of cardiac arrhythmias and sudden death in transgenic rabbits with long QT syndrome. J Clin Invest 2008;118:2246-59.

47. Hondeghem LM. Disturbances of cardiac wavelength and repolarization precede Torsade de Pointes and ventricular fibrillation in Langendorff perfused rabbit hearts. Prog Biophys Mol Biol 2016;121:3-10.

48. Lu HR, Yan G-X, Gallacher DJ. A new biomarker - index of Cardiac Electrophysiological Balance (iCEB) - plays an important role in drug-induced cardiac arrhythmias: beyond QT-prolongation and Torsades de Pointes (TdPs). J Pharmacol Toxicol Methods 2013;68:250-9.

49. Milberg P, Reinsch N, Osada N, Wasmer K, Monnig G, Stypmann J, et al. Verapamil prevents torsade de pointes by reduction of transmural dispersion of repolarization and suppression of early afterdepolarizations in an intact heart model of LQT3. Basic Res Cardiol 2005;100:365-71.

50. Tse G, Ali A, Prasad SK, Vassiliou V, Raphael CE. Atypical case of post-partum cardiomyopathy: an overlap syndrome with arrhythmogenic right ventricular cardiomyopathy? BJR Case Rep 2015;1:20150182.

51. Tse G, Ali A, Alpendurada F, Prasad S, Raphael CE, Vassiliou V. Tuberculous constrictive pericarditis. Res Cardiovasc Med 2015;4:e29614.

52. Vassiliou V, Chin C, Perperoglou A, Tse G, Ali A, Raphael C, et al. 93 ejection fraction by cardiovascular magnetic resonance predicts adverse outcomes post aortic valve replacement. Heart 2014;100:A53-4.

53. Vaillant F, Magat J, Bour P, Naulin J, Benoist D, Loyer V, et al. Magnetic resonance-compatible model of isolated working heart from large animal for multimodal assessment of cardiac function, electrophysiology and metabolism. Am J Physiol Heart Circ Physiol 2016;310:H1371-80.

54. Elkins RC. Is tissue-engineered heart valve replacement clinically applicable? Curr Cardiol Rep 2003;5:125-8.

55. Rivard AL, Suwan PT, Imaninaini K, Gallegos RP, Bianco RW. Development of a sheep model of atrial fibrillation for preclinical prosthetic valve testing. J Heart Valve Dis 2007;16:314-23.

56. Gallegos RP, Nockel PJ, Rivard AL, Bianco RW. The current state of in-vivo pre-clinical animal models for heart valve evaluation. J Heart Valve Dis 2005;14:423-32.

57. Stengl M. Experimental models of spontaneous ventricular arrhythmias and of sudden cardiac death. Physiol Res 2010;59:S25-31.

58. Chen Z, Sun B, Tse G, Jiang J, Xu W. Reversibility of both sinus node dysfunction and reduced HCN4 mRNA expression level in an atrial tachycardia pacing model of tachycardia-bradycardia syndrome in rabbit hearts. Int J Clin Exp Pathol 2016;9:8526-8531.

59. Workman AJ, MacKenzie I, Northover BJ. Do KATP channels open as a prominent and early feature during ischaemia in the Langendorff-perfused rat heart? Basic Res Cardiol 2000;95:250-60.

60. Workman AJ, MacKenzie I, Northover BJ. A K(ATP) channel opener inhibited myocardial reperfusion action potential shortening and arrhythmias. Eur J Pharmacol 2001;419:73-83.

61. Hagendorff A, Schumacher B, Kirchhoff S, Luderitz B, Willecke $\mathrm{K}$. Conduction disturbances and increased atrial vulnerability in Connexin40-deficient mice analyzed by transesophageal stimulation. Circulation 1999;99:1508-15.

62. Sun B, Qi X, Jiang J. Heptanol decreases the incidence of ischemia-induced ventricular arrhythmias through altering electrophysiological properties and connexin 43 in rat hearts. Biomed Rep 2014;2:349-53.

63. Shi S, Liu T, Wang D, Zhang Y, Liang J, Yang B, et al. Activation of $\mathrm{N}$-methyl-d-aspartate receptors reduces heart rate variability and facilitates atrial fibrillation in rats. Europace 2016 [ahead of print: pii: euw086].

64. Cyon E. Über den einfluss der temperaturänderungen auf zahl, dauer und stärke der herzschläge. Berichte über die verhandlungen der königlich sächsischen gesellschaft der wissenschaften zu Leipzig. Mathematisch-Physische Classe 1866;18:256-306. 
65. Langendorff 0 . Untersuchungen am überlebenden Säugetierherzen. Pflug Archiv 1898;61:291-332.

66. Taegtmeyer H. One hundred years ago: Oscar Langendorff and the birth of cardiac metabolism. Can J Cardiol 1995;11:1030-35.

67. Zimmer HG. The isolated perfused heart and its pioneers. News Physiol Sci 1998;13:203-10.

68. Skrzypiec-Spring M, Grotthus B, Szelag A, Schulz R. Isolated heart perfusion according to Langendorff---still viable in the new millennium. J Pharmacol Toxicol Methods 2007;55:113-26.

69 . Wiggers CJ. The innervation of the coronary vessels. Am J Physiol 1909;24:391-405.

70. Broadley KJ. The Langendorff heart preparation-reappraisal of its role as a research and teaching model for coronary vasoactive drugs. J Pharmacol Methods 1979;2:143-56.

71. Katz G, Paine WG, Tiller PM. A new method for coronary perfusion of the mammalian heart. Arch Int Pharmacodyn 1939;61:109-12.

72. Broadley KJ. An analysis of the coronary vascular responses to catecholamines, using a modified Langendorff heart preparation. Br J Pharmacol 1970;40:617-29.

73. Choy L, Yeo JM, Tse V, Chan SP, Tse G. Cardiac disease and arrhythmogenesis: mechanistic insights from mouse models. Int J Cardiol Heart Vasc 2016;12:1-10.

74. Tse G, Tse V, Yeo JM. Ventricular anti-arrhythmic effects of heptanol in hypokalaemic, Langendorff-perfused mouse hearts. Biomed Rep 2016;4:313-24.

75. Tse G, Lai ET, Lee AP, Yan BP, Wong SH. Electrophysiological mechanisms of gastrointestinal arrhythmogenesis: lessons from the heart. Front Physiol 2016;7:230.

76. Sutherland FJ, Shattock MJ, Baker KE, Hearse DJ. Mouse isolated perfused heart: characteristics and cautions. Clin Exp Pharmacol Physiol 2003;30:867-78.

77. Liao R, Podesser BK, Lim CC. The continuing evolution of the Langendorff and ejecting murine heart: new advances in cardiac phenotyping. Am J Physiol Heart Circ Physiol 2012;303:H156-67.

78. Neely JR, Rovetto MJ, Whitmer JT, Morgan HE. Effects of ischemia on function and metabolism of the isolated working rat heart. Am J Physiol 1973;225:651-8.

79. Neely JR, Liebermeister H, Battersby EJ, Morgan HE. Effect of pressure development on oxygen consumption by isolated rat heart. Am J Physiol 1967;212:804-14.

80. Bateman MG, laizzo PA. Comparative imaging of cardiac structures and function for the optimization of transcatheter approaches for valvular and structural heart disease. Int J Cardiovasc Imaging 2011;27:1223-34.

81. Chinchoy E, Soule CL, Houlton AJ, Gallagher WJ, Hjelle MA, Laske TG, et al. Isolated four-chamber working swine heart model. Ann Thorac Surg 2000;70:1607-14.

82. Martin HN, Applegrath EC. On the temperature limits of the vitality of the mammalian heart. Stud Biol Lab Johns Hopkins Univ 1890;4:275.

83. Manuck HP, Hockman CH. Central nervous system mechanisms mediating cardiac rate and rhythm. Am Heart J 1967;74:96-109.

84. Gellhorn E. The significance of the state of the central autonomic nervous system for quantitative and qualitative aspects of some cardiovascular reactions. Am Heart J 1963;67:106-20.

85. Mason DT. The autonomic nervous system and regulation of cardiovascular performance. Anesthesiology 1968;29:670-80.

86. Wolf S. Neural mechanisms in sudden cardiac death. Trans Am Clin Climatol Assoc 1968;79:158-76.
87. Coumel P. Cardiac arrhythmias and the autonomic nervous system. J Cardiovasc Electrophysiol 1993;4:338-55.

88. Sutherland FJ, Hearse DJ. The isolated blood and perfusion fluid perfused heart. Pharmacol Res 2000;41:613-27.

89. Mantravadi R, Gabris B, Liu T, Choi BR, de Groat WC, Ng GA, et al. Autonomic nerve stimulation reverses ventricular repolarization sequence in rabbit hearts. Circ Res 2007;100:e72-80.

90. Ng GA, Brack KE, Coote JH. Effects of direct sympathetic and vagus nerve stimulation on the physiology of the whole heart--a novel model of isolated Langendorff perfused rabbit heart with intact dual autonomic innervation. Exp Physiol 2001;86:319-29.

91. Brack KE, Coote JH, Ng GA. Interaction between direct sympathetic and vagus nerve stimulation on heart rate in the isolated rabbit heart. Exp Physiol 2004;89:128-39.

92. Brack KE, Coote JH, Ng GA. The effect of direct autonomic nerve stimulation on left ventricular force in the isolated innervated Langendorff perfused rabbit heart. Auton Neurosci 2006;124:69-80.

93. Brack KE, Coote JH, Ng GA. Vagus nerve stimulation inhibits the increase in $\mathrm{Ca} 2+$ transient and left ventricular force caused by sympathetic nerve stimulation but has no direct effects alone--epicardial $\mathrm{Ca} 2+$ fluorescence studies using fura-2 AM in the isolated innervated beating rabbit heart. Exp Physiol 2010;95:80-92.

94. Ng GA, Brack KE, Patel VH, Coote JH. Autonomic modulation of electrical restitution, alternans and ventricular fibrillation initiation in the isolated heart. Cardiovasc Res 2007;73:750-60.

95. Brack KE, Patel VH, Coote JH, Ng GA. Nitric oxide mediates the vagal protective effect on ventricular fibrillation via effects on action potential duration restitution in the rabbit heart. J Physiol 2007;583:695-704.

96. Ng GA, Mantravadi R, Walker WH, Ortin WG, Choi BR, de Groat $W$, et al. Sympathetic nerve stimulation produces spatial heterogeneities of action potential restitution. Heart Rhythm 2009;6:696-706.

97. Winter J, Brack KE, Coote JH, Ng GA. Cardiac contractility modulation increases action potential duration dispersion and decreases ventricular fibrillation threshold via beta1-adrenoceptor activation in the crystalloid perfused normal rabbit heart. Int J Cardiol 2014;172:144-54.

98. Ng GA. Vagal modulation of cardiac ventricular arrhythmia. Exp Physiol 2014;99:295-9.

99. Valentin JP, Hoffmann P, De Clerck F, Hammond TG, Hondeghem L. Review of the predictive value of the Langendorff heart model (Screenit system) in assessing the proarrhythmic potential of drugs. J Pharmacol Toxicol Methods 2004;49:171-81.

100. Tse G, Yeo JM, Tse V, Sun B. Gap junction inhibition by heptanol increases ventricular arrhythmogenicity by decreasing conduction velocity without affecting repolarization properties or myocardial refractoriness in Langendorff-perfused mouse hearts. Mol Med Rep 2016;14:4069-4074.

101. Tse G, Lai ET, Chan YW, Yeo JM, Yan BP. What is the arrhythmic substrate in viral myocarditis? Insights from clinical and animal studies. Front Physiol 2016;7:308.

102. Tse G, Lai ET, Yeo JM, Yan BP. Electrophysiological mechanisms of Bayés syndrome: insights from clinical and mouse studies. Front Physiol 2016;7:188.

103. Tse G, Lai ET, Tse V, Yeo JM. Molecular and electrophysiological mechanisms underlying cardiac arrhythmogenesis in diabetes mellitus. J Diabetes Res 2016:2848759. 
104. Pye MP, Cobbe SM. Arrhythmogenesis in experimental models of heart failure: the role of increased load. Cardiovasc Res 1996;32:248-57.

105. Nicolson WB, McCann GP, Brown PD, Sandilands AJ, Stafford PJ, Schlindwein FS, et al. A novel surface electrocardiogram-based marker of ventricular arrhythmia risk in patients with ischemic cardiomyopathy. J Am Heart Assoc 2012;1:e001552.

106. Nicolson WB, McCann GP, Smith MI, Sandilands AJ, Stafford PJ, Schlindwein FS, et al. Prospective evaluation of two novel ECG-based restitution biomarkers for prediction of sudden cardiac death risk in ischaemic cardiomyopathy. Heart 2014;100:1878-85.

107. Tse G. Both transmural dispersion of repolarization and transmural dispersion of refractoriness are poor predictors of arrhythmogenicity: a role for the index of Cardiac Electrophysiological Balance (QT/QRS)? J Geriatr Cardiol 2016;13:813-4.

108. Tse G. (Tpeak-Tend)/QRS and (Tpeak-Tend)/(QT x QRS): novel markers for predicting arrhythmic risk in the Brugada syndrome. Europace 2016; pii: euw194.

109. Tse G, Yan BP. Traditional and novel electrocardiographic conduction and repolarization markers of sudden cardiac death. Europace 2016; pii: euw280.

110. Tse G. Novel conduction-repolarization indices for the stratification of arrhythmic risk. J Geriatr Cardiol 2016;13:811-812.

111. Curtis MJ, Hancox JC, Farkas A, Wainwright CL, Stables CL, Saint DA, et al. The Lambeth Conventions (II): Guidelines for the study of animal and human ventricular and supraventricular arrhythmias. Pharmacol Ther 2013;139:213-48.

112. Krebs HA, Henseleit K. Untersuchungen ueber die Harnstoffbildung im Tierkoerper. Hoppe-Seyler's Z Physiol Chem 1932;210:33-6.
113. Reichelt ME, Willems L, Hack BA, Peart JN, Headrick JP. Cardiac and coronary function in the Langendorff-perfused mouse heart model. Exp Physiol 2009;94:54-70.

114. Bing RJ, Siegel A, Ungar I, Gilbert M. Studies on fat, ketone and amino acid metabolism. Am J Med 1954;16:504-15.

115. Belke DD, Larsen TS, Lopaschuk GD, Severson DL. Glucose and fatty acid metabolism in the isolated working mouse heart. Am J Physiol 1999;277:R1210-7.

116. Bell RM, Mocanu MM, Yellon DM. Retrograde heart perfusion: the Langendorff technique of isolated heart perfusion. J Mol Cell Cardiol 2011;50:940-50.

117. Bing RJ. Some aspects of biochemistry of myocardial infarction. Cell Mol Life Sci 2001;58:351-5.

118. Qiu Y, Hearse DJ. Comparison of ischemic vulnerability and responsiveness to cardioplegic protection in crystalloid-perfused versus blood-perfused hearts. J Thorac Cardiovasc Surg 1992;103:960-8.

119. Armitage WJ, Pegg DE. An evaluation of colloidal solutions for normothermic perfusion of rabbit hearts: an improved perfusate containing Haemaccel. Cryobiology 1977;14:428-34.

120. Zausig YA, Chappell D, Becker BF, Potschka D, Busse H, Nixdorf $\mathrm{K}$, et al. The impact of crystalloidal and colloidal infusion preparations on coronary vascular integrity, interstitial oedema and cardiac performance in isolated hearts. Crit Care 2013;17:R203.

121. White CW, Hasanally D, Mundt P, Li Y, Xiang B, Klein J, et al. A whole blood-based perfusate provides superior preservation of myocardial function during ex vivo heart perfusion. J Heart Lung Transplant 2015;34:113-21.

122. Pasini E, Solfrini R, Bachetti T, Marino M, Bernocchi P, Visioli F, et al. The blood perfused isolated heart: characterization of the model. Basic Res Cardiol 1999;94:215-22. 
Reproduced with permission of copyright owner.

Further reproduction prohibited without permission. 